\title{
Lumbosacral radiculopathy as a rare manifestation of giant cell arteritis: A case report and review of the literature.
}

\author{
Nazanin Naderi* \\ Department of Rheumatology, Danderyd Hospital, Stockholm, Sweden
}

\begin{abstract}
Giant cell arteritis (GCA) is the most common form of primary vasculitis, affecting primarily the large and middle sized arteries in people aged 50 years or older. It is associated with a spectrum of neurological manifestations, the most frequent being neuro-ophtalmic, others are mononeuritis simplex, mononeuritis multiplex, diffuse peripheral polyneuropathy, acute confusional states, spinal cord infarction and TIA/stroke. Radiculopathy/plexopathy is rarely described.
\end{abstract}

This report present a case with lumbosacral radiculopathy, perceived as steroid-induced myopathy.

Keywords: Giant cell arteritis, Neurological complications, Peripheral neuropathy, Lumbosacral plexus, Lumbar radiculopathy, Peripheral nerve, Lumbar nerve root.

Accepted on July 17, 2018

\section{Case}

\section{History}

A 84-year old female with polymyalgia rheumatica (PMR) with disease onset at the age of 62 and with ongoing prednisolone (PRD) $12.5 \mathrm{mg} / \mathrm{d}$, was referred to the rheumatology department in December 2012 due to progressive proximal muscle weakness of the lower extremities over the last 2 years, considered as steroid-induced myopathy.

At disease onset September 1991, the patient suffered acute onset of pains in the calf muscles and shortly after also pains in the neck and upper arms, erythrocyte sedimentation rate (ESR) was $90 \mathrm{~mm} / 1 \mathrm{~h}$, no other laboratory measurements was done. PMR was diagnosed by her general practitioner and PRD was instituted with a prompt response. PRD was then tapered during one year to $5 \mathrm{mg} / \mathrm{d}$ when she flared leading to escalation to 15 $20 \mathrm{mg} / \mathrm{d}$. This pattern was repeated again and again over the years. She managed to become PRD free once for three years before a relapse of PMR symptoms and PRD was re-established. Neither at disease onset nor later did she display any ischemic symptoms.

\section{Examination}

The medical history and physical examination was unremarkable, except for cushingoid features and difficulty rising from a chair, squatting position and climbing stairs.

Routine laboratory analysis and serology (RF, CCP, P-and C-ANCA) at the initial visit were normal except for a mild rise of the inflammatory markers: Leukocytes $10.0 \times 10^{9} / \mathrm{L}$, C-reactive protein (CRP) $9.9 \mathrm{mg} / \mathrm{L}$, ESR $36 \mathrm{~mm} / 1 \mathrm{~h}$.

\section{Investigations}

Structured PRD tapering with blood work prior to each reduction was employed, looking for emerging symptoms. The PRD tapering extending over a period of six months. Flare occurred with recurrence of PMR symptoms on a PRD dose of $2.5 \mathrm{mg} / \mathrm{d}$ and $5 \mathrm{mg} / \mathrm{d}$ q.o.d. (ESR 43, CRP 44).

To determine a possible underlying GCA as cause of relapsing disease, temporal artery biopsy (TAB) was performed, with classic transmural inflammation (Figure 1).

A positron emission tomography-computed tomography was conducted to evaluate the extend of inflammation, showing bilateral involvement of the vertebral arteries, patchy involvement of common carotid and iliac arteries, the entire femoral and popliteal arteries but no aortic involvement (Figure 2).

A magnetic resonance imaging of the lumbar column showed no signs of vertebral abnormality, disc herniation, spinal stenosis or radicular compressing process, only mild to moderate facet joint osteoarthritis at the levels of L4-L5 and L5-S1.

Electromyography (EMG) with electro-neurography (ENG) showed multiple bilateral lumbosacral rhizopathies of old date with mild-moderate axonal degeneration at the L4-L5 and L5S1 levels with no signs of myopathy.

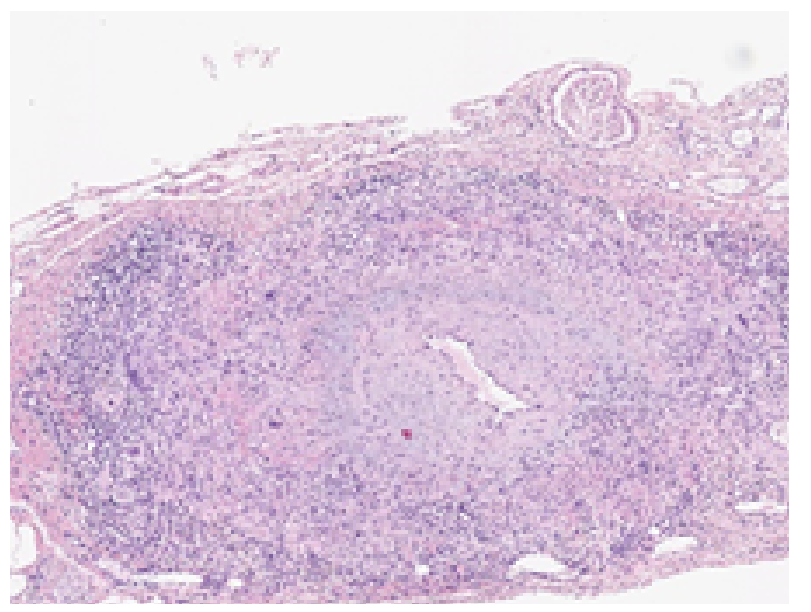

Figure 1. Temporal artery biopsy with full-blown transmural inflammation. 


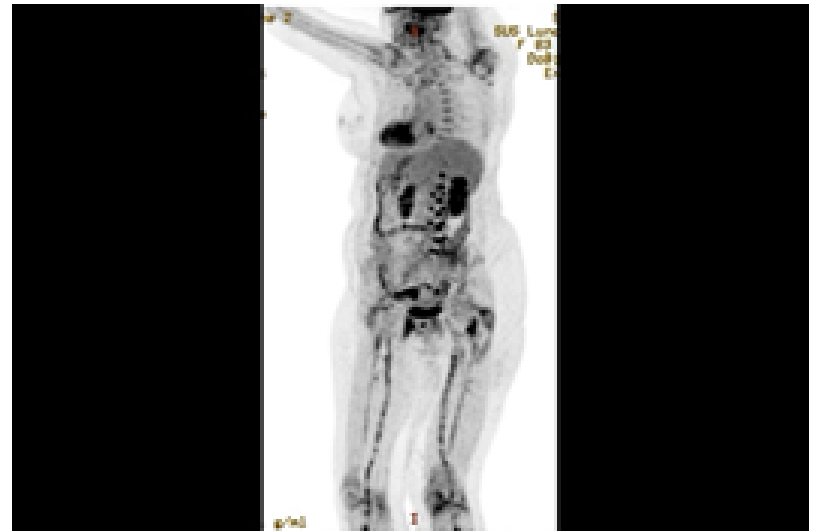

Figure 2. PET-CT with widespread vasculitis.

A neurological evaluation was conducted that lasted for ten months (ending October 2014), no apparent other cause could be found. During this investigation, the patient suffered two, about fifteen minutes long, episodes of sloping of the upper body to the right combined with weakness. CT angiography of the brain showed no intracranial vasculitis. The episodes were considered as transient ischemic attacks secondary to microembolism from the inflamed neck arteries.

\section{Treatment}

The change of diagnose to GCA did not lead to PRD escalation, partly due to the wishes of the patient and partly because of, at this point, long-term symptoms (about 3.8 years) deeming the chance of recovery or improvement very low. After completed investigation leflunomide was initiated.

\section{Discussion}

To the best of my knowledge there are no previous cases describing clinically pure PMR with histopathological and imaging evidence of underlying active and widespread GCA or with a disease duration of 23 years.

Contrary to the previously held belief that GCA and PMR are self-limiting conditions, vasculitis may persists [1]. It is debated whether PMR and GCA are two different diseases or just different manifestations of the same, as: I) $40-60 \%$ of the GCA patients have PMR symptoms [2-5], II) PMR symptoms can develop before, simultaneously or after GCA onset [1,2,69], III) about $2-15 \%$ of patients with pure PMR, later develop clinical GCA [9], and IV) in so-called "pure PMR" up to $41 \%$ have subclinical underlying vasculitis, as shown by biopsy $[10,11]$ by ultrasound $[12]$ and $31-80 \%$ by imaging studies with PET $[13,14]$.

There are very few cases published with regard to radiculopathy of the lumbar nerve roots in GCA. Caselli et al. described two TAB-positive patients, a 61-year old female with a left and a 65-year old male with a right L5 radiculopathy, both EMG/ ENG verified. In these patients prednisone $60 \mathrm{mg} / \mathrm{d}$ was started after 2 months of onset of the neurologic symptoms. The glucocorticoid response with regard to neurologic symptoms, total regress within 6 months, was described for one patient [15]. Burton et al. described a 69-year old male, with clinical and electrophysiological abnormalities and post-mortem histopathological evidence of GCA involving the lumbosacral plexus and lumbar nerve roots [16]. Gross et al. described a 62-year old female with a 3-months history of progressive weakness and severely impaired muscle strength in the shoulder and hip girdles. EMG findings were consistent with denervation in all four extremities. Prednisone $60 \mathrm{mg} / \mathrm{d}$ was initiated and full recovery noted after six weeks [17].

Steroid-induced myopathy (SIM) is always the first suspected culprit when a patient with longstanding steroid treatment complains of muscle weakness, as was the case here. The patient was perceived to suffer from SIM, beginning two years earlier, but had not. and did not develop any subjective proximal muscle weakness affecting the neck flexors or the shoulder girdle. This is atypical and a red flag, since in chronic (or classic) SIM muscle weakness progresses insidiously, affects proximal muscles of both upper and lower limbs and the neck flexors, although pelvic girdle muscles are often first and more severely affected than the arms [18-20].

As to the pathogenecis of radiculopathy/plexopathy, one must suspect an ischemic mechanism such as vasculitis compromising nutrient arteries supplying the nerve roots/truncs, vasculitis of the vasa nervorum or both. Caselli et al. described a GCA patient with polyneuropathy of the feet undergoing both artery and nerve biopsy, histopathology revealed vasculitis of the medium and large arteries with ischemic necrosis of nerve fascicles but no vasa nervorum affection [15]. Pfadenhauer et al. described a TAB positive patient with left arm weakness, autopsy showed arteritis in an artery supplying the brachial nerve plexus [21]. In the case by Burton et al. autopsy demonstrated nerve roots with patchy axonal loss and fibrosis consistent with ischemic injury. Peripheral nerves including brachial plexus, femoral and median nerves were also examined, finding a few fascicles with evidence of axonal loss. Scattered small blood vessels associated with spinal nerve roots had lymphocytic cuffs, and radicular arteries of the lower cervical roots and their branches displayed a florid transmural arteritis with infiltration of lymphocytes, macrophages, multinucleated giant cells plus destructed internal elastic lamina and intimal proliferation.

In conclusion one must first and foremost suspect, investigate and rule out neurological complication of GCA. Steroid-induced myopathy should be considered a diagnosis of exclusion, as the present case illustrates. It may be of value to investigate an underlying GCA when facing a protracted PMR course.

\section{References}

1. Naderi N. Giant Cell Arteritis-A Report on Systematic Physical Evaluation and Large Vessel Involvement as a Prognostic Risk Factor for Complicated Disease Course, Real Life Data. Arch Gen Intern Med. 2018;2:10-6.

2. Salvarani C, Hunder GG. Musculoskeletal manifestations in a population-based cohort of patients with giant cell arteritis. Arthritis Rheum. 1999;42:1259-66.

3. Salvarani C, Gabriel SE, O'Fallon WM, et al. Epidemiology of polymyalgia rheumatica in Olmsted County, Minnesota, 1970-1991. Arthritis Rheum. 1995;38:369-73.

4. Franzén P, Sutinen S, von Knorring J. Giant cell arteritis and polymyalgia rheumatica in a region of Finland: an 
epidemiologic, clinical and pathologic study, 1984-1988. J Rheumatol. 1992;19:273-6.

5. Salvarani C, Gabriel SE, O'Fallon WM, et al. The incidence of giant cell arteritis in Olmsted County, Minnesota: apparent fluctuations in a cyclic pattern. Ann Intern Med. 1995;123:192-4.

6. Cantini F, Niccoli L, Storri L, et al. Are polymyalgia rheumatica and giant cell arteritis the same disease? Semin Arthritis Rheum. 2004;33:294-301.

7. Smith CA, Fidler WJ, Pinals RS. The epidemiology of giant cell arteritis. Report of a Ten-Year Study in Shelby County, Tennessee. Arthritis Rheum. 26:1214-9.

8. Rynes RI, Mika P, Bartholomew LE. Development of giant cell (temporal) arteritis in a patient "adequately" treated for polymyalgia rheumatica. Ann Rheum Dis. 1977;36:88-90

9. Liozon E, de Boysson H, Dalmay F, et al. Development of Giant Cell Arteritis after Treating Polymyalgia or Peripheral Arthritis: A Retrospective Case-control Study. J Rheumatol. 2018;45:678-85.

10. Fauchald P, Rygvold O, Øystese B. Temporal Arteritis and Polymyalgia Rheumatica: Clinical and Biopsy Findings. Ann Intern Med. 1972;77:845-52.

11. Hamrin B. Polymyalgia arteritica. Acta Med Scand Suppl. 1972;533:1-131.

12. Chrysidis S, Lage-Hansen PR, Diamantopoulos AP. Polymyalgia rheumatica relapse and "silence" large vessel vasculitis. Is there any association? [Internet]. ACR Meeting Abstracts, number 2770. 2014.
13. Blockmans D, Maes A, Stroobants S, et al. New arguments for a vasculitic nature of polymyalgia rheumatica using positron emission tomography. Rheumatol. 1999;38:444-7.

14. Blockmans D, Ceuninck LD, Vanderschueren S, et al. Repetitive 18-fluorodeoxyglucose positron emission tomography in isolated polymyalgia rheumatica: a prospective study in 35 patients. Rheumatol. 2007;46:6727.

15. Caselli RJ, Daube JR, Hunder GG, et al. Peripheral neuropathic syndromes in giant cell (temporal) arteritis. Neurol. 1988;38:685-9.

16. Burton E, Winer J, Barber P. Giant cell arteritis of the cervical radicular vessels presenting with diaphragmatic weakness. J Neurol Neurosurg Psychiatry. 1999;67:223-6.

17. Gross MD, Borkin MH, Rupp S. Unusual electromyographic findings in a patient with polymyalgia rheumatica. Arthritis Rheum. 1979;22:277-80.

18. Guis S, Mattéi JP, Lioté F. Drug-induced and toxic myopathies. Best Pract Res Clin Rheumatol. 2003;17:877907.

19. Pereira RMR, Freire de Carvalho J. Glucocorticoid-induced myopathy. Jt Bone Spine Rev Rhum. 2011;78:41-4.

20. Alshekhlee A, Kaminski HJ, Ruff RL. Neuromuscular manifestations of endocrine disorders. Neurol Clin. 2002;20:35-58.

21. Pfadenhauer K, Roesler A, Golling A. The involvement of the peripheral nervous system in biopsy proven active giant cell arteritis. J Neurol. 2007;254:751-5.

\section{*Correspondence to:}

Nazanin Naderi

Department of Rheumatology, Danderyd Hospital, Stockholm

Sweden

E-mail: nazanin.naderi.f@gmail.com 